\title{
El "Consenso de Monterrey": Financiar el desarrollo
}

- Francisco Javier Ibisate

\section{El alivio de la pobreza}

En el documento inicial, que sirve de base a la Conferencia Internacional de Monterrey, celebrada del 18 al 22 de marzo de 2002, encontramos repetidas referencias literales a la Declaración del Milenio, cumbre convocada por las Naciones Unidas en Nueva York, el mes de septiembre de 2000. "La globalización es muy beneficiosa para algunos y es potencialmente beneficiosa para todos, pero sólo si los Estados trabajan conjuntamente para que estos beneficios lleguen a todo su pueblo". El apartado tercero de esta cumbre lleva por título: 'El desarrollo y la erradicación de la pobreza'. "No escatimaremos esfuerzos para liberar a nuestros semejantes, hombres, mujeres y niños, de las condiciones abyectas y deshumanizadoras de la pobreza extrema a la que están en la actualidad sometidos más de mil millones de seres humanos. Nos preocupan los obstáculos a que se enfrentan los países en desarrollo para movilizar los recursos necesarios para financiar su desarrollo sostenible...Decidimos, asimismo, reducir a la mitad para el año 2015 el porcentaje de habitantes del planeta cuyos ingresos sean inferiores a un dólar por día y el de las personas que padecen hambre".

Luego del 11 de septiembre se reúne en Ottawa, en noviembre de 2001, el Grupo de los 20 (G-20), una alianza contra los fondos del terrorismo. Estos ministros de economía y gobernadores de bancos centrales prevén que los paises pobres serán los más perjudicados por el actual enfriamiento de la economía, agravada por los sucesos del 11 de septiembre. "La pobreza en muchos paises en desarrollo se agravará, porque estos acontecimientos han agudizado el previo enfriamiento de la economía global, que ya habia llevado a menores exportacio- 
nes y caída de los precios de las materias primas". Un delegado del Banco Mundial deja entrever que puede anudarse una relación entre pobreza e inseguridad. A partir del 11 de septiembre, "el mundo es diferente, más integrado y tiene que haber más unión entre países pobres y desarrollados, porque la alienación, la pobreza, la violencia, la ira, son una amenaza para la paz y la prosperidad en todo el mundo". James Wolfensohn agrega que "el Banco Mundial asume que debe ayudar más a los países pobres"(citado en Realidad, 2002, p. 8). En la conferencia de Monterrey surgirán ciertas tensiones entre norteamericanos y europeos porque la administración Bush desea recortar el carácter universal del Banco Mundial.

En la $56^{\mathrm{a}}$ Asamblea General de Naciones Unidas, que tuvo lugar en la ciudad de Nueva York, durante el mes de noviembre de 2001, Kofi Annan hace frente al unilateralismo de George W. Bush: "Estamos tentados de concentrar todos nuestras energías en la lucha contra el terrorismo, pero esto sería conceder la victoria al terrorismo, porque los problemas a que nos habiamos enfrentado el 10 septiembre (cumbre del Milenio, año 2000) no han cambiado, sino que se hacen más urgentes. Para evitar el enfrentamiento mutuamente destructivo entre las mismas civilizaciones es necesario dar una esperanza real a millones de personas cercadas por la pobreza, los conflictos y las enfermedades". En visperas de esa cumbre Kofi Annan habia dicho: "Las Naciones Unidas deben esforzarse por combatir la pobreza, el SIDA y otros conflictos, incluidos los cambios climáticos; todos estos problemas pueden alimentar el terrorismo". (Ibidem, p. 11)

En el $32^{\circ}$ foro económico de Davos, reunido este año en Nueva York, se habla de 'economía frágil', economía de la incertidumbre y de la inseguridad, de desigualdad; "la globalización de la ira se ha acelerado con el rápido crecimiento de las desigualdades sociales. Antes que un mundo estable hay que lograr un mundo justo". El foro social de Porto Alegre desarrolla estos problemas en los cuatro ejes de su programa de desarrollo mundial". (ECA 2002; pp. 62.)

En la preparación de la conferencia de Monterrey, Kofi Annan contó con el apoyo de su representante especial, Michel Candessus, ex director del FMI, quien, en su discurso de despedida en la cumbre de Bangkok, Tailandia, convocada en febrero de 2000, planteara el fracaso de la globalización en su pretensión de reducir la pobreza. "La respuesta es que aún no se ha demostrado que la globalización se preocupe lo suficiente por el problema más grave de esta era, la pobreza, o que sea capaz de resolverlo. La creciente brecha entre ricos y pobres y el abismo que separa a los países más ricos y los más pobres son moralmente inadmisibles, económicamente ineficientes $\mathrm{y}$, desde un punto de vista social, potencialmente explosivos. Hoy es evidente que no basta aumentar el tamaño de la torta, la forma en que se reparte es esencial para el dinamismo del desarrollo. Si no ofrecemos esperanza a los pobres, la confrontación, la violencia y las conmociones civiles terminarán socavando la estructura de la sociedad. En nin- 
guna parte podemos permitirnos el lujo de hacer caso omiso de la pobreza, pero es en los paises más pobres donde ya no puede tolerarse la extrema pobreza. Es nuestro deber aunar esfuerzos para aliviar el sufrimiento"... Este texto de Michel Camdessus, que advierte la posible conexión de pobreza y violencia, será casi literalmente repetido por el presidente de Francia, Jacques Chirac, en Monterrey, donde varios delegados ven en la extendida pobreza una de las causales del presente terrorismo.

Previo a la cumbre de Monterrey, se reunieron unos treinta ministros de economía y gobernadores de bancos centrales en el Centro de Desarrollo Internacional de Washington, el día 20 de febrero de este año, para adelantar los grandes lineamientos del alivio de la pobreza. Michel Camdessus instó a las grandes potencias a cumplir sus compromisos. El nuevo milenio ha traído consigo enormes desafios y horror, pero también motivos para la esperanza, como los compromisos contraidos en Nueva York (el mes de septiembre de 2000) para erradicar la pobreza y fortalecer los cimientos de una alianza mundial establecidos en Génova (en julio de 2001), poco resaltados por la prensa mundial.

Centró su discurso en cuatro ejes: 1. La cooperación. "La clave del éxito es la cooperación entre los países industriales y los paises en desarrollo. Los primeros deben poner las necesidades de los paises pobres en el centro de la atención mundial. 2. Paz. Una vez concluidas las operaciones militares en Afganistán, la segunda fase contra el terrorismo para Estados Unidos y sus aliados exige una acción coordinada para hacer frente a la violencia en sus propias raíces en todo el mundo, en forma de pobreza generalizada y desesperación. Esta nueva fase requerirá solidaridad a escala mundial en el marco de una coalición lo más amplia posible para el desarrollo. Monterrey es una ocasión ideal para analizar las extraordinarias oportunidades de cambio constructivo y no deberiamos desaprovechar esta oportunidad. 3. Gestión de gobierno. Los paises en desarrollo, comenzando por el continente africano, se han comprometido a llevar a cabo politicas de una manera más participativa, más transparente y más honesta. 4. Financiamiento. Lo más importante es que en Monterrey surja el compromiso renovado de los paises industrializados de cumplir la promesa de proporcionar 50.000 millones de dólares al año en "asistencia oficial al desarrollo" (AOD), promoviendo la mutua rendición de cuentas de los donantes y de los beneficiarios, "aumentar el número de economías eficientes" en el mundo en desarrollo $y$, con el tiempo, ayudar a establecer un sistema de supervisión regional entre los paises en desarrollo. Camdessus exhortó a los paises ricos a no reducir la AOD.

En esta reunión, el financiero y filántropo George Soros propuso la utilización de los derechos especiales de giro (DEG) como una forma de financiamiento del desarrollo. Los paises ricos efectuarian una donación de 18.000 millones de dólares a un fondo fiduciario para los países pobres, en el marco de una emisión 
especial de DEG de 27.000 millones de dólares, aprobada por el FMI en 1997. En Monterrey se hará mención de esta propuesta de G. Soros. El FMI designaría a un grupo de expertos, que en forma independiente del mismo FMI, llevarían el control de calidad mediante la selección y análisis de proyectos aceptables, que competirian por esta asistencia. Los donantes podrían participar en la selección de proyectos dentro de una lista final. El Premio Nobel de Economía 2001, Joseph Stiglitz, apoyó y detalló aún más la propuesta de George Soros. Pero el Secretario del Tesoro de los EE.UU., Paul O'Neil, se opuso a fijar montos fijos, el comprometido $0,7 \%$ del PIB, delegando a los gobiernos donantes las condiciones y situaciones en que deberían otorgarse estas ayudas, como lo harán los delegados del gobierno USA en Monterrey. Esta postura no fue del agrado de las tres personas antes mencionadas y la misma tensión aparecerá en Monterrey. (Boletin del FMI, volumen $31, \mathrm{~N}^{\circ}$ 5, 18 de marzo de 2002)

Adelantando un comentario a la cumbre de Monterrey, José Antonio Alonso, de la Universidad Complutense de Madrid, se agrega al coro de quienes no esperan mucho de la presente reunión, que no irá muy allá de las buenas intenciones. "A lo largo de la década de los noventa, Naciones Unidas puso en marcha una activa dinámica de cumbres y conferencias internacionales en las que, de modo gradual, se definieron los componentes de una agenda consensuada de desarrollo. Lamentablemente, gran parte de aquellos acuerdos quedaron relegados al capitulo de las buenas intenciones. La ausencia de mandato ejecutivo de Naciones Unidas explica en parte este resultado, que es acorde con el cómodo recurso de los gobiemos a proclamar buenos propósitos sin comprometer las reformas que los hacen posibles. Iniciado el nuevo siglo, aquellos problemas que animaron las cumbres siguen vigentes, mientras nuevos motivos de preocupación emergen como consecuencia del carácter asimétrico del proceso de la globalización en curso. La interdependencia creciente entre países y mercados ha puesto en evidencia, con más claridad que nunca, que es difícil la gobernabilidad de un mundo crecientemente integrado en el que rigen intensas desigualdades. Combatir la pobreza se convierte, entonces, no sólo en un imperativo moral, sino también en una exigencia práctica para aminorar los niveles de inestabilidad y riesgo del sistema internacional".

Suponiendo que los grandes estados quieren el fin, no dan muestras de querer aplicar los medios. "Semejante acción correcta no puede, sin embargo, ser dejada en manos del mercado; entre otras cosas, porque el propio mercado alienta la desigualdad, al favorecer el crecimiento y la exclusión como polos contradictorios de una misma realidad. El proceso de globalización ejemplifica esta dinámica: si, por una parte, activa los factores promotores del crecimiento como consecuencia de la ampliación de los mercados, por otra, incrementa las tensiones distributivas de la desigual capacidad de los paises para acceder a las ventajas de unos espacios económicos más integrados. Por ello, es necesario promover un cambio en el orden internacional que amplie las oportunidades de progre- 
so de los países más pobres. Los datos confirman este juicio. A lo largo de las dos últimas décadas, los mercados de capital experimentaron una expansión sin precedentes en la historia, pero a los países menos desarrollados apenas llegó el $0,5 \%$ de la inversión extranjera; para estos países, la ayuda al desarrollo supone más del $80 \%$ de los recursos que reciben del exterior, pero la cuantía de la ayuda ha descendido en un $20 \%$ en términos reales a lo largo de la pasada década; la globalización convalida el papel del comercio como motor del crecimiento, pero los costos que genera el proteccionismo de los paises ricos en el mundo en desarrollo supera, en las más modestas afirmaciones, entre 100.000 y los 150.000 millones de dólares (entre el doble y el triple de la ayuda que reciben); la inestabilidad cambiaria obliga a una política de reservas, pero, en los paises en desarrollo, ello comporta una salida neta de recursos hacia los mercados industriales. Los datos referidos no agotan el diagnóstico, pero son suficientes para evidenciar las dificultades a que se enfrentan los paises en desarrollo para acceder a oportunidades de progreso en el sistema actual".

"Para tratar estos temas, Naciones Unidas convocó la Conferencia Intergubernamental de Monterrey. El propósito de la conferencia es doble: en primer lugar, hacer viables los objetivos de la Declaración del Milenio, que básicamente se refieren a la reducción a la mitad de la pobreza antes del año 2015, corrigiendo, además, alguna de sus manifestaciones más lacerantes y, en segundo lugar, promover cambios en el marco normativo y de las relaciones internacionales para garantizar el carácter incluyente de la globalización, de modo que sus potenciales efectos positivos alcancen a todos los paises. En relación con estos objetivos se definió una amplia agenda integrada por los diversos componentes de la financiación del desarrollo: recursos domésticos, inversión extranjera, comercio internacional, deuda externa, ayuda al desarrollo y otros temas relacionados con el funcionamiento agregado del sistema económico. Pese a la relevancia de las materias abordadas, los resultados no dejan mucho espacio para el optimismo, a juzgar por el contenido del documento final acordado con antelación al inicio de las sesiones". ("Sin respuestas de Monterrey". El Pais, 22 de marzo de 2002)

\section{Un título ambiguo}

Los redactores del documento final desean ganar la benevolencia del club de los donantes, aunque en número y espacio son más las exigencias planteadas a los paises en desarrollo. Este dificil equilibrio pretende conducir a un consenso ("Consenso de Monterrey"), enmarcado en una visión económica al agrado de los donantes. No se trata de trastocar sino de hacer más equitativo el modelo, y esto va a generar fuertes tensiones. Las ONG, presentes en Monterrey, lo ven como una clonación del "Consenso de Washington", de inspiración neoliberal. En 1990, las grandes instituciones intemacionales centraban las politicas económicas para el desarrollo en los siguientes criterios: "la subordinación del papel

El "Consenso de Monterey": Financiar el desorrollo 
del Estado al del mercado; la liberalización de los tipos de cambio, de interés y de inversiones extranjeras directas; la disciplina fiscal; la máxima participación posible en los intercambios internacionales y la promoción del comercio exterior; la privatización de las empresas públicas; la consideración del progreso social, no como una prioridad, sino como una consecuencia del crecimiento económico; la garantía absoluta de los derechos de propiedad privada, y la afirmación de que sólo existe un modelo racional de desarrollo". (Vidal Beneyto J.: "El desarrollo como negocio". El País, 23 de marzo de 2002)

La filosofia de Monterrey se fundamenta en "políticas racionales, la promoción del comercio, las privatizaciones, el buen gobierno", sin definir positivamente este concepto, aunque se repite que la comupción es una de las caracteristicas de su reverso. Los sucesos del 11 septiembre han gestado la promesa de un aumento de la ayuda de los paises ricos para el alivio de la pobreza, resaltando, al menos, dos obstáculos a este proceso: las subvenciones agricolas de los paises ricos se elevan a 327 miles de millones de dólares, el doble de las exportaciones del Sur, al mismo tiempo que la tradicional corrupción de tantos gobiernos esteriliza el alivio de la pobreza. ("L'onde de choc du 11 septembre relance la lutte contre la pavreté dans le monde". Le Monde, 21 de marzo de 2002)

El "Consenso de Monterrey" es un título ambiguo porque el consenso se centra en que la pobreza no se ha aliviado, sino que se ha agravado a nivel mundial. Pero no hay consenso en las políticas que deben aplicarse para el alivio de la misma pobreza. En este punto surgen divergencias entre la Unión Europea (UE) y los Estados Unidos. Hay divergencias entre el Norte y el Sur por las medidas que se quieren aplicar y por las que se dejan en el tintero, es decir, los problemas que se silencian. Hay divergencias porque se afirma, en forma dogmática, que "el libre comercio promete democracia y desarrollo". Hay divergencias, porque se recalca, con mucha razón, que la corrupción de muchos gobiernos del Sur es un obstáculo al desarrollo, pero no se habla mucho de la corrupción de gobiernos del Norte como obstáculo al desarrollo. Hay divergencias, "porque se mantiene una sospechosa asimetría entre las abundantes reformas que se reclaman a los paises en desarrollo y las más bien vagas alusiones que se hacen a modificaciones del sistema internacional". Hay divergencias, porque pocos hablan de la "mundialización de la solidaridad".

\section{Los compromisos de Monterrey}

Sin duda hay y habrá lecturas diferentes del documento enviado a los delegados: Proyecto de documento final de la Conferencia Internacional sobre la Financiación para el Desarrollo. Consenso de Monterrey. Un concentrado documento, dieciocho páginas en letra pequeña, precedido por el estribillo: "Nosotros, Jefes de Estado, nos comprometemos"...Como dice el catedrático José Antonio Alonso, son muchas más las reformas que se exigen a los países en 
desarrollo que los compromisos concretos que se esperan de los países ricos. Cuando a la elevada pobreza se suma el pesado fardo de la deuda externa, las barreras comerciales, las escasas alternativas de capitales financieros, muchos de los compromisos firmados no pasan a ser más que buenas intenciones. Los jefes de Estado asistentes, ¿habrán leido íntegramente el documento? ¿Habrán consultado las ideas centrales de sus breves discursos o son ellas más bien fruto de las alianzas o discrepancias ideológicas con los grandes donantes? En resumen, ¿se trata de un compromiso viable?

El diario Le Monde nos hace el servicio de sintetizar los grandes compromisos de los jefes de Estado: "Nosotros, los jefes de Estado". He aquí un resumen del resumen.

"Nuestro objetivo es eliminar la pobreza, alcanzar un crecimiento económico sostenible, que lleve a un desarrollo mundial abierto a todos y equitativo. Los recursos movilizados son todavia insuficientes a tal fin. Por ello, se hace necesario un nuevo compromiso entre países desarrollados y en vías de desarrollo. Nos comprometemos a aplicar políticas racionales, instaurar el buen gobierno y asegurar la primacía del derecho. Nos esforzaremos por movilizar los recursos nacionales, atraer flujos internacionales, promover el comercio internacional que es el motor del desarrollo; intensificar la cooperación financiera y técnica internacional para el desarrollo, un financiamiento viable y un alivio de la deuda externa; reforzar la coherencia de los sistemas monetarios, financieros y comerciales internacionales".

"Los ataques terroristas del 11 septiembre han agravado la desaceleración de la economia mundial, reduciendo su tasa de crecimiento. Por ello urge que todos los actores colaboren muy unidos para lograr un crecimiento económico sostenido y resolver los problemas de financiamiento del desarrollo a largo plazo. Nuestra voluntad de trabajar unidos es más fuerte que nunca. Cada país es el responsable de su desarrollo económico y social. La mundialización ofrece perspectivas, asi como crea problemas. Los países en desarrollo y los emergentes se enfrentan a dificultades mayores. La mundialización debiera beneficiar a todos, en forma equitativa. Un buen gobierno es la primera condición para un desarrollo durable. La libertad, la seguridad, la estabilidad interior, el respeto a los derechos humanos, incluidos el derecho al desarrollo, el Estado de derecho, la igualdad de género y la voluntad nacional de crear sociedades justas y democráticas son también necesarias y sinérgicas. Una prioridad es la lucha contra la corrupción a todos los niveles... Un sistema comercial multilateral y universal, bien reglamentado y abierto, no discriminatorio sino equitativo, concebido como un verdadero instrumento de la liberación del intercambio, puede ser un gran factor favorable para el desarrollo mundial". (Le Monde, 22 de marzo de 2002)

Los redactores del borrador de Monterrey, que se convierte en el documento final, tratan de afinar los prerrequisitos que deben entallarse en el sistema co-

El "Consenso de Monterrey": Financiar el desarrollo 
mercial para que realmente se convierta en factor de desarrollo mundial. Todavia están presentes las tensiones de la reunión de la OMC en Doha, Qatar, celebrada el mes de noviembre de 200! (Realidad 2002, pp. 14-19) y las más recientes demandas de los foros económicos y social de Davos-Nueva York y Porto Alegre, en febrero de 2002 ( $E C A, 2002$; pp. 61-67) Que ia mundialización ofrece tantas perspectivas como problemas se ha venido repitiendo desde la OMC de Seattle hasta la Declaración del Milenio: "Creemos que la tarea fundamental a que nos enfrentamos hoy es conseguir que la mundialización se convierta en una fuerza positiva para todos los habitantes del mundo, ya que si bien ofrece grandes posibilidades, en la actualidad sus beneficios se distribuyen de forma muy desigual, al igual que sus costos". El programa del foro social de Porto Alegre recoge con más amplitud los grandes vectores de la globalización: Comercio exterior, flujos de capitales, organismos internacionales, alivio de la deuda externa, los sistemas monetarios, financieros y comerciales mundiales...y los derechos humanos, económicos, sociales y culturales. (ECA, 2002; pp 63-64) Que estos vectores de la globalización se integren al servicio del desarrollo duradero mundial dependerá, primordialmente, de la buena voluntad de los pajses desarrollados y de las instituciones internacionales que ellos controlan. Las Naciones Unidas no cuentan, hoy por hoy, con una autoridad ejecutiva, aunque todos los jefes de Estados digan: "nosotros nos comprometemos". ¿A qué se han comprometido los jefes de Estado en Monterrey?

\section{El alivio de la pobreza}

La primera palabra la tienen los donantes que se han comprometido, sin fecha muy precisa, al financiamiento del desarrollo, aunque a niveles inferiores al prometido $0,7 \%$ del PIB en 1969. Mucho dependerá de cómo visualicen el alivio de la pobreza. Los corresponsales hablan de divergencias entre la Unión Europea (EU) y los Estados Unidos respecto a las modalidades y exigencias del alivio de la pobreza. Ha sido el presidente de Francia, Jacques Chirac, quien ha dado el toque humano y moral al alivio de la pobreza, presentándola como "la defensa de la "mundialización de la solidaridad", retomando algunas expresiones, antes citadas, de Michel Camdessus. Jacques Chirac pone el dedo en dos llagas. "Nuestro mundo se enfrenta con el terrorismo fanático, con los poderosos tentáculos del crimen organizado y de los traficantes de la droga. Las naciones que temen ver su identidad aplastada por la aplanadora de una mundialización incontrolada, a veces buscan refugiarse en la nostalgia de tiempos pasados. Lo que está en juego en Monterrey no es sólo el financiamiento del desarrollo. Es la unificación de los Estados ante la cuestión más hiriente de nuestro tiempo. ¿Cómo poner fin a una situación moralmente inaceptable, politicamente peligrosa, económicamente absurda, que es un mundo donde la acumulación creciente de riquezas no es capaz de hacer que los más pobres salgan de su pobreza?".

Jacques Chirac se alegra de que tanto la UE como los EE.UU. hayan prome- 
$0,7 \%$. En su discurso de seis minutos dijo que sólo la ayuda no basta. "Hay que prolongar la concesión de derechos especiales de giro, una aplicación más generosa de la anulación de la deuda a los paises más pobres y un endeudamiento mayor a los países de ingresos medios". Propuso a los miembros de la ONU realizar, en la próxima década, cinco proyectos: Destinar el $0,7 \%$ de la riqueza de los países industrializados; un acuerdo sobre nuevos recursos (una "tasa" aún no especificada); la creación de un Consejo de Seguridad Económica y Social "para asegurar todos juntos la gestión de los bienes público mundiales, y la realización de los objetivos de Kioto, que todos los paises deben ratificar". Hay que buscar "el interés general del planeta. Sólo uniendo nuestros esfuerzos podemos gerenciar solidariamente los bienes públicos mundiales, que son el clima, los bosques, el agua, el aire, patrimonio común de la humanidad. Es tiempo de hacer conciencia de que la mundialización de la economia exige la mundialización de la solidaridad" ("Jacques Chirac plaide pour la mondialisation de la solidarité" Le Monde, 22 de febrero de 2002). Chirac tuvo su discurso poco antes que George W. Bush, único gobierno que no ha ratificado el protocolo de Kioto. El presidente Chirac es uno de los pocos jefes de Estado que advierte sobre el posible circuito pobreza-terrorismo, recalca lo inmoral y lo peligroso de la desigualdad social, no deja en el tintero los problemas del deterioro ecológico, enuncia la conveniencia de aplicar una "tasa" (que otros académicos han propuesto con mayor detalle) y agrega una agenda de cinco puntos a los miembros de la ONU.

En este orden de aportes, el secretario del Tesoro británico, Gordon Brown, pide a la comunidad internacional realizar "una guerra contra la pobreza" y presenta un argumento bien preciso: "Hay un acuerdo creciente en que, igual que luchamos juntos contra el terrorismo, debemos luchar juntos contra la pobreza". James Wolfensohn, presidente del Banco Mundial, tradujo esta divisa con otras palabras. "El 11 de septiembre, la crisis de Afganistán, llegó a Wall Street, al Pentágono y a un campo de Pennsylvania, y el muro imaginario que dividía al primer mundo del tercer mundo se derrumbó estrepitosamente. El creer en ese muro nos ha hecho pensar durante mucho tiempo que un mundo donde cada minuto muere una mujer en el parto es un mundo normal. Es tiempo de desmantelar ese muro, de reconocer que en este mundo unificado la pobreza es nuestro enemigo común. La guerra por librar es contra la pobreza".

Gordon y Wolfensohn se unen a quienes "insisten en la necesidad de que la cumbre produzca un compromiso de aumentar la ayuda para el desarrollo a unos 50.000 millones de dólares durante los próximos años". Esta ayuda se ha venido reduciendo en la década de los noventa, pasando la tasa media de $0,35 \%$ a $0,22 \%$ del PIB. Los EE.UU. se comprometieron inicialmente con 5.000 millones de dólares, que luego prometieron duplicar; ayuda siempre condicionada a ciertos requisitos. La UE se comprometería con 7.000 millones de dólares durante cuatro años. Estas promesas quedaban bastante por debajo de los 50.000 millo-

El "Consenso de Monterrey": Financior el desanollo 
nes de dólares necesarios para el alivio de la pobreza. Esta ayuda es inferior a la sexta parte de las subvenciones agrícolas de los países ricos y sólo costaría el $1 \%$ de las ventas de los mismos países.

El informe británico agrega que la ayuda ha ganado en eficiencia mientras que su monto se reduce. "En 1990, mil millones de dólares sacaban a unas 120.000 personas de la pobreza extrema en forma permanente. En 1997, con los mismos mil millones se rescataba a 284.000 personas". Gordon Brown concluye que la ayuda al desarrollo si tiene un efecto positivo sobre el alivio de la pobreza". Wolfensohn compara la resistencia de los países ricos a incrementar la ayuda con el hecho de que "son responsables del $90 \%$ del valor multimillonario del comercio de armas en el mundo. Las armas que están contribuyendo a los mismos conflictos que todos nosotros decimos condenar y en cuya eliminación debemos gastar más dinero". ( "El Reino Unido pide a la comunidad internacional una guerra contra la pobreza". El Pais, 21 de marzo de 2002)

El discurso más esperado y, por lo mismo, más expuesto a la crítica, es el del presidente George W. Bush. La posición del gobiemo de EE.UU. plantea bastantes interrogantes. Dias antes de la reunión de Monterrey, Bush quiso ganarse unos puntos políticos anunciando el incremento de 5.000 millones de dólares en ayuda a los paises pobres; dicha ayuda sería depositada en una especie de cuenta corriente, llamada Fondo del Milenio. Criticado por lo reducido de la ayuda, se elevó el monto a 10.000 millones de dólares en el trienio, dando la impresión de que el plan se improvisó sobre la marcha. "Soy la primera persona en admitir que no teniamos cifras muy claras", dijo Condoleeza Rice. El presidente Bush prometió agregar otros 5.000 millones de dólares en 2007 a países pobres que cumplan determinadas condiciones. Aparte de que estas cifras no sobrepasan el $0,15 \%$ del PIB, surgen las divergencias sobre el modo en que Estados Unidos distribuirá la ayuda.

Al parecer, bajo inspiración o presión del secretario del Tesoro de EE.UU., Paul O'Neil, el 50\% de la ayuda se haría en forma de "donación" a los países más pobres. O'Neil no oculta su desconfianza sobre el éxito de la ayuda pública al desarrollo: "no sirve para nada". Se opone a la petición de Wolfensohn y Gordon Brown de elevar la ayuda de 50.000 millones de dólares a 100.000 millones de dólares, e ironizó el informe del Banco Mundial sobre la eficiencia de su ayuda al desarrollo: "si una parte importante de la población vive con menos de un dólar al día, esto significa que después de cincuenta años no se ha tenido mayor éxito", reconociendo que no había leído el informe. La idea de Paul O'Neil y Alan Larson, encargado de asuntos económicos, es transformar el $50 \%$ de préstamos del $\mathrm{BM}$ en donaciones: "Cuando un país lucha contra el SIDA, o se halla en situación postbélica, devastado por la guerra o por conflictos étnicos, es un error proporcionarle asistencia bajo la condición de 'préstamos' porque ello derivaria en una deuda insostenible". La idea de George W. 
Bush seria no utilizar la ventanilla préstamos, sino hacer lo antes posible donaciones a países tan necesitados que, de todas maneras, no podrian reembolsar.

Los europeos no están de acuerdo con esta modalidad porque significaría que el gobierno norteamericano vuelve a actualizar la tesis de la 'Comisión Meltzer', planteada en la cumbre de Primavera del FMI-BM, en abril de 2000. Según el profesor Allan Meltzer (¿asesorado por Jeffrey Sachs?), habría que reducir las funciones del FMI a las crisis financieras y las del BM a las ayudas a países más pobres, reduciendo su carácter más universal. Los países debían recurrir más al mercado de capitales privados, en su mayoría norteamericanos, reduciendo, al mismo tiempo, los aportes del Gobierno de EE.UU. a ambas instituciones. (ECA, 2000; pp. 1024-1025)

Esta tesis fue entonces y ahora debatida por los europeos, por los paises en desarrollo (Cumbre de Bangkok) y por los gobernadores del FMI y BM. "Pedir al Banco Mundial que renuncie a sus préstamos significa asfixiarlo financieramente, porque el reembolso de los préstamos es lo que permite hacer nuevos préstamos". Wolfensohn ha dicho: "No estoy en contra de las donaciones que juegan un papel importante en los campos de la educación, la lucha contra el SIDA y en ciertas situaciones de postconflicto. El problema es la capacidad de financiarlas. Si nuestros accionistas están dispuestos a aumentar su contribución para reemplazar los fondos transformados en donación, yo estoy feliz. A ellos toca decidir". La razón de fondo es que para el gobierno de EE.UU. los ejes principales del desarrollo son el comercio y la inversión privada. ( Babette Stern: "Americains et Européens divergent sur la fracture mondiale". Le Monde, 19 de marzo de 2002)

Como dijera Joseph Stiglitz a los delegados del G-7, congregados en Génova, el mes de julio de 2001: "Se predica el libre comercio como el evangelio en todas partes, pero parece que los países no hacen caso de su propio mensaje; sus mercados permanecen cerrados a muchos de los productos de los países en desarrollo, subsidian sus agriculturas en forma masiva, lo que hace imposible que los paises en desarrollo puedan competir. El mensaje del G-7 parecer ser: hagan lo que decimos, no lo que hacemos".

Esto es lo que viene a decir George W. Bush en su discurso de Monterrey: "Estoy aqui para reafirmar la voluntad de los Estados Unidos de llevar la esperanza y abrir los horizontes de los pueblos más necesitados e invitar a poner en marcha un nuevo pacto para el desarrollo, que se caracterice por una mayor responsabilidad de los países ricos asi como de los paises pobres". A la base de este pacto estaria la lucha contra la corrupción, la inversión en educación y el compromiso con el libre comercio. "Los paises en desarrollo necesitan un acceso más amplio a los mercados de los paises ricos. Debemos también reducir las barreras comerciales entre los mismos países en desarrollo". En esos mismos

El "Consenso de Monterrey": Financior el desarrollo 
días de debatia en la sede de la OMC en Ginebra los aranceles impuestos por EE.UU. a las importaciones del acero.

"Nosotros luchamos contra la pobreza con la esperanza de que ello sea una respuesta al terrorismo. Atacamos la pobreza, la indigencia, la falta de educación y a los ineficientes gobiernos que, con frecuencia, permiten que se den situaciones que los terroristas aprovechan para su causa". Aunque miembros del gobierno lo nieguen, la ayuda norteamericana para el desarrollo se enmarca en la política antiterrorista. Además, Bush quiere resultados concretos, económicos y políticos. "Desde hace décadas, el éxito de la ayuda al desarrollo se ha medido por el monto de recursos gastados. Verter dinero sobre un estéril inmovilismo poco ayuda a los pobres, e incluso puede retrasar las reformas y el progreso. La pobreza no es la causa del terrorismo. Sin embargo, una pobreza persistente y la represión pueden llevar a la desesperación. Debemos unir una ayuda mayor con las reformas políticas, jurídicas y económicas. Insistir sobre estas reformas es un esfuerzo de compasión... Las naciones desarrolladas tienen el deber, no sólo de distribuir su riqueza, sino también de promover las fuentes que promueven la riqueza: libertad económica, libertad politica, Estado de derecho y derechos del hombre". Bush agrega: "Trabajaré con el Congreso para que estos recursos estén disponibles en los próximos meses". Las Secretarías del Estado y del Tesoro de los EE.UU. redactarán un "riguroso" reglamento con los criterios de la distribución de la ayuda para el alivio de la pobreza. Una semana antes, Bush habia dicho que se deben respetar estos tres criterios: "un gobierno justo, una inversión social, un apoyo a la libertad económica" (Bush anuncia que ayudará sólo a los países pobres que liberalicen su economía". El Pais, 23 de marzo de 2002. "George W. Bush est partisan d'une aide conditionée". Le Monde, 23 de marzo de 2002) "La nouvelle aproche compasionelle du président George Bush". Le Monde, 23 de marzo de 2002)

El discurso de Bush es tan diáfano como simplista: la solución de la pobreza está en la libertad política, económica y en el libre mercado. El buen gobierno y las politicas racionales se refieren a la aceptación de la economía de mercado y, por añadidura, serán el Tesoro y la Secretaría de los EE.UU. quienes definan la lista de los buenos gobiernos acreditados para recibir la ayuda. La financiación del desarrollo no nace de un proceso de contrición, de una 'globalización de la solidaridad', sino de una temerosa atrición, por cuanto la pobreza puede alimentar el terrorismo. Todas estas verdades las vino a predicar, día seguido, a Perú, buscando un aliado más a la lucha antiterrorista, y en San Salvador, unos aliados al libre comercio, que crea democracia y desarrollo. Por lo que toca a las ayudas anunciadas no hay tiempos ni cantidades definidas y todo queda a la merced de los requisitos que deban cumplir los paises prestatarios. Por eso se dijo que el discurso de Bush era el más esperado y el más proclive a la crítica.

Terminada la conferencia los corresponsales de Le Monde afirman que los Estados se comprometen con el minimo de la ayuda al desarrollo. "La reunión a 
Estados se comprometen con el mínimo de la ayuda al desarrollo. "La reunión a puerta cerrada de Jefes de Estado no ha permitido mejorar un texto calificado por muchos de minimalista". Los europeos, especialmente Chirac, han defendido un aumento sustancial de la ayuda pública al desarrollo, mientras que el gobierno de los Estados Unidos la condiciona a los resultados: "Verter dinero sobre un inmovilismo estéril es poco productivo para ayudar a los pobres y puede, por el contrario, retrasar al avance de las reformas". Por su parte, los paises pobres, "incluso aceptando las condiciones pactadas (economía de mercado, buen gobierno, lucha contra la comupción, democracia) han hecho saber que están cansados de promesas no cumplidas y que los países ricos no pueden pedirles apostar por los beneficios de la mundialización sin darles los medios para evitar el naufragio. Todos han reclamado un acceso, sin discriminación, a los mercados occidentales, en particular al sector agricola del que vive más de la mitad de la población del Sur. Han reclamado esfuerzos suplementarios para aliviar el fardo de la deuda". La inversión privada extranjera se concentra en países situados a medio camino del primer mundo, China, Brasil, Malasia..., mientras que para el resto de países esta ayuda internacional sigue siendo irreemplazable". La conferencia de Monterrey no ha dejado la impresión de ser "una coalición mundial contra la pobreza". ("A Monterrey les Etats s'engagent a minime sur l'aide au développement". Le Monde, 24 de marzo de 2002)

\section{El comercio internacional como promotor del desarrollo}

Desde la cumbre de la OMC en Seattle, el cual se efectuó en diciembre de 1999, hasta la reciente cumbre en Doha, Qatar, de noviembre de 2001, y el más reciente foro social de Porto Alegre, llevado a cabo durante el mes de febrero de 2002 , sigue la controversia sobre los costos cuantitativos y cualitativos que el libre comercio genera al Tercer Mundo. Baste recordar, una vez más, que J. Stiglitz fue galardonado con el Premio Nobel de economía 2001 por su "Teoría de las asimetrias". Sin hacer historia ni teoria sobre el comercio internacional, se recogen simplemente algunos párrafos del documento firmado en Monterrey, donde las Naciones Unidas tratan de ganar la benevolencia de los paises desarrollados para que cumplan lo que predican y generar así nuevas esperanzas a los países en desarrollo. Se mezcla la doctrina con las recomendaciones, aunque bastantes jefes de Estado dejaron plasmada, en sus breves discursos, una doctrina dogmática y por ello inconmovible. En el documento se miden cuidadosamente las palabras, las condiciones y los calificativos, así como aparecen los claroscuros de la teoría y de la realidad.

"26. Un sistema comercial multilateral abierto a la participación de todos, basado en normas, no discriminatorio y equitativo, junto con la liberalización real del comercio puede estimular apreciablemente el desarrollo en todo el mundo y beneficiar a las partes en todas las etapas del desarrollo. A este respecto, reafirmamos nuestro compromiso de fomentar la liberalización del comercio y 
aseguramos de que el comercio contribuya plenamente a promover el crecimiento económico, el empleo y el desarrollo de todos los países. Por lo tanto, acogemos con satisfacción las decisiones de la Organización Mundial del Comercio en el sentido de que las necesidades y los intereses de los paises en desarrollo constituyen el elemento central de su programa de trabajo y nos comprometemos a ponerlas en práctica".

"27. El comercio es, en muchos casos, la fuente externa más importante de financiación para el desarrollo, pero para que los beneficie verdaderamente, los paises en desarrollo y los países con economías en transición deben establecer instituciones y políticas apropiadas a mejorar las existentes. La liberalización efectiva del comercio es un elemento importante de la estrategia de desarrollo sostenible de un país. La expansión del comercio y de la inversión extranjera directa podría estimular el crecimiento económico y ser una importante fuente de empleo".

"28. Tenemos presentes las cuestiones relativas al comercio intemacional que interesan particularmente a los países en desarrollo y a los países con economías en transición, en lo que se refiere a aumentar su capacidad de financiar su propio desarrollo. Estas cuestiones son, entre otras, las siguientes: las barreras comerciales, los subsidios y otras medidas que distorsionan el comercio, en particular en sectores de especial interés para las exportaciones de los países en desarrollo, incluida la agricultura; la aplicación indebida de medidas antidumping, las barreras técnicas y las medidas sanitarias y fito-sanitarias; la liberalización del comercio en industrias manufactureras de gran densidad de mano de obra, la liberación del comercio de productos agrícolas; el comercio de los servicios; las crestas arancelarias, y la elevada cuantía y la escalada de aranceles y las barreras no arancelarias; la circulación de personas; la falta de reconocimiento de los derechos de propiedad intelectual para la protección de los conocimientos tradicionales y el folklore; la transferencia de conocimientos y tecnología; la aplicación e interpretación del Acuerdo sobre aspectos de los derechos de propiedad intelectual relacionados con el comercio, de manera que sirvan de apoyo a la salud pública, y la necesidad de incluir en los convenios comerciales disposiciones que prevean un trato especial y diferente para los paises en desarrollo, para que estos instrumentos sean más precisos y eficaces y tengan aplicación en la práctica".

"31. Cumpliremos los compromisos contraidos en Doha de abordar el problema de la marginación de los paises menos adelantados en el comercio internacional, así como el programa de trabajo aprobado para examinar cuestiones relativas al comercio de las economías de pequeño tamaño.

"32. Como parte de nuestros esfuerzos para crear un mejor sistema de comercio mundial, también nos comprometemos a promover la importancia de los acuerdos regionales y subregionales y de las zonas de libre comercio, en confor- 
financieras internacionales, en particular a los bancos regionales de desarrollo, a que sigan apoyando proyectos que fomenten la integración subregional y regional de los países en desarrollo y los países con economías en transición".

“36. Invitamos a las instituciones financieras y de desarrollo multilaterales y bilaterales a que amplien y coordinen su labor para eliminar gradualmente las limitaciones de la oferta y destinen más recursos a ese fin; mejoren la infraestructura del comercio; diversifiquen la capacidad de exportación y apoyen un aumento del contenido tecnológico de las exportaciones; fortalezcan el desarrollo institucional y estimulen la productividad y la competitividad en general. Con este fin, invitamos también a los donantes bilaterales y a las instituciones financieras internacionales y regionales, asi como a los organismos, fondos y programas pertinentes de las Naciones Unidas, a que redoblen su apoyo a los servicios de capacitación, desarrollo de la capacidad, fortalecimiento institucional y apoyo al comercio".

“37. También es necesaria la ayuda multilateral para mitigar las consecuencias del estancamiento de los ingresos de exportación de los países que aún dependen considerablemente de exportaciones de productos básicos... Asimismo, es importante proporcionar a los productores de productos básicos de los paises en desarrollo los medios necesarios para asegurarse contra posible riesgos, incluidos los desastres naturales. Invitamos además a los donantes bilaterales y a los organismos multilaterales de ayuda a que redoblen su apoyo a los programas de diversificación de las exportaciones de esos países".

“38. En apoyo del proceso iniciado en Doha, se debería prestar atención inmediata al fomento y fortalecimiento de la participación plena y activa de los países en desarrollo en las negociaciones multilaterales, sobre todo la de los países menos adelantados".

Inmersos, como estamos, en las firmas y ratificaciones de varios acuerdos de libre comercio, no está de más el visualizar los vericuetos en que se mueven la teoría y la realidad concreta del comercio internacional. A modo de apostilla, Mike Moore, director de la OMC, presente en Monterrey, renovó sus criticas a las barreras comerciales: "Si se abrieran las fronteras, los paises en desarrollo ganarian diez veces más que los 10.000 de dólares al año que podría costar la extensión de la educación a todo el mundo. La renta mundial aumentaría 2,8 billones de dólares y 320 millones de personas saldrían de la pobreza para 2015 . Los 50.000 millones de dólares adicionales de ayuda que, según el Banco Mundial, se necesitan para alcanzar los objetivos de la Cumbre del Milenio, son también una minucia comparados con los 1.000 millones de dólares diarios que los países gastan en subvenciones a la agricultura, con los entre 70.000 y 110.000 millones de dólares que les cuestan anualmente sus medidas de protección oficial, o con los 10.000 millones de dólares que EE.UU. pierde anualmente por las restricciones que impone a las importaciones textiles". ("Bush anuncia que ayu- 
dará sólo a los países que liberalicen su economía". El Pais, 23 de febrero de 2002)

Lo paradójico de Monterrey, y otras cumbres mundiales, es que los oferentes de ayuda externa aparecen como los chicos buenos de la película, cuando en realidad no alcanzan a devolver sino una mínima parte de lo que han usurpado en forma draconiana con el 'evangelio' del libre comercio internacional. Las breves estadisticas de Mike Moore confirman la teoría de las asimetrías de J. Stiglitz. Por ello es necesario aclarar los conceptos y las realidades: estamos a favor del libre comercio y del efecto multiplicador del comercio exterior, algo que ya se conocía desde la época de los fenicios. Pero también es cierto que desde la época del mercantilismo, las relaciones asimétricas entre las metrópolis y las colonias muestran que, desgraciadamente, el libre comercio "no es un comercio libre". Por ello, los manifestantes pacíficos vienen cantando, de cumbre en cumbre hasta Porto Alegre: "Otro FMI, otro BM, otra OMC", y también, "otros gobiernos menos corruptos en los países en desarrollo".

\section{La corrupción: un obstáculo para salir de la pobreza}

El documento de Monterrey, en su numeral 13, enuncia un nuevo compromiso: "Una de nuestras prioridades es la lucha contra la corrupción en todos los niveles. La corrupción es un grave obstáculo que entorpece la movilización y asignación eficiente de recursos que deberían destinarse a actividades indispensables para erradicar la pobreza y promover un desarrollo económico sostenible". La corrupción tiene un cercano parentesco con la contaminación del medio ambiente porque deteriora la salud económica. La corrupción se expande porque para que haya corrupción hacen falta dos: el que ofrece y el que acepta, el que enseña y el que aprende, el que actúa y el que guarda silencio, el que se va y el que se queda, y todos los que piensan que es un modo usual de ganarse la vida. Por eso, es dificil definir la corrupción, asignarle límites concretos, porque siempre encuentra nuevas formas de expandirse y de contagiar a más personas. No es exagerado hablar de la mundialización de la corrupción porque también los grandes modelos económicos se presentaron como 'el fin de la historia' y lo que han logrado es deteriolarla. Pocos gobiernos y pocas grandes instituciones pueden tirar la primera piedra, aunque en Monterrey algún gobierno ha pretendido hacerlo.

En esta cumbre se parcela el ámbito de la corrupción porque su objetivo mayor es incrementar el financiamiento del desarrollo y el alivio de la pobreza. Se supone que no hay corrupción en financiar el alivio de la pobreza, por cuanto sería un acto de compasión y misericordia. El documento de Monterrey se concentra en la malversación de fondos de parte de gobiernos e instituciones receptoras de esta ayuda. "Después de tantos años de transferencias de recursos a los países menos desarrollados, los paises donantes se plantean la razón de que una 
gran parte de ellos continúen en la misma situación de pobreza y subdesarrollo. Muchos piensan que la razón del fracaso está en haber puesto el énfasis sólo en las transferencias de recursos y haber descuidado cuestiones como la corrupción de muchos de esos gobiernos y el control del destino de los recursos transferidos. Muchos países, en condiciones de miseria y sin apenas infraestructura, están abrumados por la deuda externa, porque el dinero que recibieron no sirvió a beneficiar al país, sino a sus corruptos gobernantes".

Ha sido el gobierno de los EE.UU. el que más ha insistido en condicionar la ayuda a los gobiernos que combatan la corrupción, porque se exigen resultados reales. Esto significa que también hubo corrupción en los donantes que vertieron grandes sumas de dinero a gobiernos afines o no molestos en el plano político y que en nada beneficiaron a los más pobres. Si en Monterrey se ha logrado que los paises donantes 'prometan' acrecentar su ayuda, es necesario que los gobiernos o los países receptores se comprometan a luchar contra la corrupción a todos los niveles. El control de la corrupción debe hacerse a dúo.

Se pueden espigar algunos testimonios. "Un tema pendiente es la forma en que se pueden repatriar recursos económicos sacados de los países en vías de desarrollo y transferidos a bancos de los países industrializados", dijo Kofi Annan. La conferencia de Monterrey "pretende profundizar el actual proceso hacia la reestructuración de pagos y la eventual condonación de la servidumbre de los préstamos concedidos en su día a sátrapas y bandoleros con despacho de ministro. La carga es intolerable para América Latina", dijo la mexicana Marta Bárcena, del Centro de Estudios de la Globalidad. "El realismo busca en México medidas más audaces contra una deuda que, en buena medida, apuntaló dictaduras y populismos, enriqueció a presidentes, funcionarios y empresarios cómplices, fue transferida a cuentas suizas o absorbida por el analfabetismo político". "Pero también es cierto que los paises industrializados cometieron muchos errores en la ejecución de los programas de ayuda a sus ex colonias, según admiten los gobiernos donantes. El dinero fue concedido a tiranos, a funcionarios ladrones 0 se perdía en los vericuetos de la corrupción. Sólo así se explica que la renta per cápita del Africa subsahariana no haya aumentado desde hace casi medio siglo".

Los corresponsales de El Pais se entretienen en citar, con más detalle, los escándalos y fechorías de algunos representativos artistas de la corrupción: Un ejemplo es el 'Negro Durazo', jefe policial mexicano, que recibió un doctorado honoris causa, durante la presidencia de José López Portillo, siendo el pillaje su única maestria. "Psicópatas con banda de emperador depredaron África y Asia; paises enteros fueron latifundios de sátrapas bananeros, y la coalición intelectual contra el comunismo prohijó tiranos como el congoleño Mobutu, que se hizo construir una pista de aterrizaje en su pueblo para recibir al Concorde. Miles y miles de millones de dólares, escamoteados a sociedades famélicas, sufragaron flotas de Mercedes Benz, la zapatería de lujo de la filipina Imelda Marcos,

El "Consenso de Monteney": Financiar el desanollo 
mientras la deuda externa del Tercer Mundo trepaba hasta los dos billones de dólares. Una buena parte recaló en cuentas extranjeras, paraísos fiscales y palacetes en Miami o en la Riviera francesa".

Aparecen en lista las recientes investigaciones en contra del ex presidente Arnoldo Alemán, acusado de haber amasado una fortuna de 250 millones de dólares, o el actual presidente de Guatemala, Alfonso Portillo, acusado, con otros miembros de su gobierno, del blanqueo de unos 300 millones de dólares. Se agregan los casos de Carlos Menen, Alberto Fujimori y su asesor Vladimiro Montesinos. Pudiera agregarse el escándalo de los "nuevos zares" de Rusia, que, bajo la presidencia del aletargado Boris Yeltsin, llevaron a cabo una 'apropiación desvergonzada' de grandes empresas públicas, adquiridas con créditos estatales a un precio casi treinta veces inferior a su valor real. Sin duda otros artistas del pillaje público respiren porque no han aparecido en la lista. J. J. Aznarez termina su comentario con un chiste, que roza el sarcasmo, aplicado a la "calaña' de América Latina: "¿qué es la moral?; pues un árbol que da moras" ("Caudillos contra el desarrollo". El Pais, 24 de marzo de 2002)

La cumbre de Monterrey viene a avalar los reclamos de los foros sociales de Porto Alegre, celebrados en 2001 y 2002, que unen el problema de la corrupción con el pesado fardo de la deuda externa. "La anulación de la deuda de los paises en desarrollo se impone como una de las reivindicaciones más fuertes". Se sugieren algunas medidas prácticas. "Se crearán tribunales populares para juzgar la legitimidad de las deudas contraidas por las autoridades, como en el caso peruano, país que compró aviones Mirage a Francia. Se discutió la creación de un organismo de arbitraje internacional para evaluar la responsabilidad tanto de los deudores como de los acreedores... La deuda es impagable e injusta y ya ha sido pagada con el hambre, el dolor y la miseria de nuestro pueblo. Es fundamental no pagar la deuda porque el pueblo no la contrajo". Se organizó el tribunal popular de seis miembros, entre ellos el Premio Nobel de la Paz, Adolfo Pérez Esquivel. El veredicto fue: "la deuda de estos paises es injusta e insostenible", incluso "odiosa"; una noción de derecho internacional que existe desde 1920: "un pueblo puede rechazar el pago de una deuda de un régimen anterior, si se prueba que el gobierno la utilizó para beneficio propio".

"Al poner en el banquillo a la deuda externa se pone en el banquillo, no sólo al FMI, sino también a tantos gobernantes corruptos que han hecho negocio propio con una deuda que empobrece a sus pueblos. De la misma manera que han sido llevados a juicio ex gobernantes y militares por abusos policíacos y exterminio de personas, crecen las voces de quienes reclaman que los tribunales apliquen justicia, con efecto retroactivo y sin amnistías, en casos patentes de robo, 'con guante blanco', de lo que se da para que viva el pueblo. El problema es que la corrupción dificilmente juzga la corrupción". (ECA, 2000, pp. 73-74) Cuando a un pais se le acusa — desde otro país- de que su administración de 
justicia es ineficiente y corrupta, además de la lamentación no estaría de más un momento de reflexión.

En Monterrey se dijeron otras frases paradójicas. "Cuando estemos cien por cien seguros de que un individuo robó fondos públicos, no lo vamos a dejar entrar en Estados Unidos", declaró Otto Reich, jefe de la Secretaría de Estado para Asuntos Interamericanos. La frase suena moralizante y ojalá comiencen a cumplirla porque los sentenciados serían bastantes. Lo paradójico de la frase es que existen otras formas de expoliar los fondos públicos de los países en desarrollo: el comportamiento del libre comercio internacional, las condiciones exigidas por la inversión extranjera (el Acuerdo Multisectorial de Inversión), el despojo de cuantiosos recursos naturales, el irrespeto de las normas de la OIT de parte de algunas multinacionales, la exportación clandestina de productos transgénicos, el mismo proceso de la deuda externa y, muy en resumen, el creerse los inventores y actores de la moral internacional y de la seguridad duradera. A la pregunta: ¿qué es la moral?, también bastantes personeros norteamericanos responderían: 'Un árbol que da moras'. Otras corrupciones son la causa mayor de la creciente pobreza; entre ellas el negarse a una autocrítica de la actual globalización, "donde la acumulación creciente de riquezas no es capaz de hacer que los más pobres salgan de su pobreza".

\section{Declaraciones sin compromisos}

"El documento, conocido como Consenso de Monterrey, confirma que la comunidad internacional es más proclive a la formulación de declaraciones que a la adopción de compromisos... Nada hay en el documento de Monterrey que garantice este objetivo". De poco servirá la ayuda externa si se mantienen los obstáculos que el sistema internacional impone a los países en desarrollo. "Nada nuevo hay en materia de inversión, pese a la manifiesta selectividad de los flujos; nada frente a la volatilidad de los capitales, pese al coste que comporta en términos de inestabilidad para los paises en desarrollo; nada respecto a los paraisos fiscales, la transparencia fiscal o la corrupción internacional, pese a los recursos que extravía; nada en materia de comercio, pese al costo que comporta el proteccionismo selectivo de los países industriales y su discrecional recurso a las barreras arancelarias, y nada frente a la deuda externa, pese a la importante sangría que supone para buena parte del mundo en desarrollo".

"Incluso aquellas propuestas más sugerentes del primer borrador, el llamado Informe Zedillo (como la creación de un foro internacional para estudiar el impacto de la inversión extranjera, el recurso a un mecanismo arbitral para el tratamiento de la insolvencia soberana, la adopción de marcos fiscales de medio plazo para programar el esfuerzo inversor o el establecimiento de una instancia de coordinación en materia fiscal) han quedado virtualmente eliminadas del documento final. Como eliminada quedó toda referencia a los bienes públicos 
globales, como nuevo ámbito de legitimación de la cooperación internacional para el desarrollo".

"Al tiempo, se presta muy escasa atención a los cambios institucionales requeridos para democratizar el marco de las instituciones encargadas de gobernar la globalización. En el presente, los paises desarrollados acumulan el $17 \%$ de los votos en Naciones Unidas y el $23 \%$ en la OMC, pero llegan a más del $60 \%$ en el caso de las instituciones de Bretton Woods. Es dificil que el FMI pueda desempeñar su tarea de vigilancia y de generación de normas y estándares internacionales con legitimidad mientras esté sometido a tan anómala estructura representativa. Pero, acaso, la carencia básica del documento es la inexistencia de referencia alguna a nuevos recursos para promover el desarrollo, salvo una vaga alusión a los derechos especiales de giro. Una carencia tanto menos justificable cuando ésta era una materia básica de la conferencia. No sólo se desconsideran propuestas imaginativas, como la planteada por Stiglitz para dar un uso activo a las reservas o la sugerida por Soros para crear un fondo internacional financiado con derechos especiales de giro, sino que tampoco se contemplan algunas propuestas de mayor tradición como el impuesto Tobin o la tasa sobre el liso de combustible de carbono".

"En suma, en el pasado la comunidad internacional consideró que bastaba con reformar las economías en desarrollo para que el progreso surgiera de forma espontánea. Buena parte de las economias acometieron las reformas, pero el desarrollo sigue sin haber llegado. Es hora de reconocer el carácter sospechosamente unilateral de aquella terapia, es dificil que haya progreso para los países pobres si no se modifica también el marco internacional en el que aquellos paises se integran. Acordar esas reformas era la tarea de la Conferencia de Monterrey, y, en este ámbito, permanecemos hasta ahora sin respuesta". (Alonso J. A. : "Sin respuestas de Monterrey". El Pais, 22 de marzo de 2002)

De momento nos tenemos que contentar con que los países industrializados cumplan con sus promesas de incrementar sus ayudas al alivio de la pobreza, que es una violencia anterior y más extendida que el parcial "terrorismo" que ha gestado el 'pánico' norteamericano y su seguridad duradera; lo mismo que seguiremos esperando que se haga algo por combatir 'a todos los niveles' la tradicional corrupción de autoridades e instituciones del tercer mundo, muchas veces prohijada por la corrupción de las autoridades del primer mundo. 